\title{
CARACTERÍSTICAS DA LEITURA EM LIVRO ELETRÔNICO INTERATIVO: UMA REVISÃO INTEGRATIVA
}

\author{
Berenice Santos Gonçalves* \\ Gabriela de Moraes Damé*
}

\begin{abstract}
RESUMO: Neste artigo buscou-se elaborar uma análise crítica das informações coletadas a partir de uma revisão integrativa dos termos-chave correlatos à leitura e ao texto em livros eletrônicos interativos. A partir dos referidos termos, presentes em artigos das bases de dados identificadas a partir do Portal Capes de Periódicos, objetivou-se demarcar e sistematizar as descobertas e as pesquisas realizadas nos últimos cinco anos. Assim, a pesquisa foi conduzida a partir da seguinte questão: quais as características do texto e, por consequência, da leitura em livro eletrônico, a partir do ano de 2008, nas três mais relevantes bases de dados encontradas na pesquisa das palavras-chave definidas e revisadas ao longo do processo. A partir dos resultados foi possível obter um panorama da temática enunciada e identificar lacunas para pesquisas futuras. São raros, ainda, os estudos sobre a experiência de leitura no livro eletrônico interativo. As pesquisas encontradas divergem quanto à linguagem da interface, pois a leitura depende da configuração de um mapa cognitivo individual e subjetivo e os estudos sobre, no meio digital, contribuem para o aperfeiçoamento das interfaces de livros.
\end{abstract}

PALAVRAS-CHAVE: Livro eletrônico. Hipermídia. Leitura. Texto.

O objeto de estudo do presente artigo é o processo de leitura no livro eletrônico. O livro eletrônico, em discussão, não consiste em uma "imitação" do livro tradicional, como nos aponta Pires (2010, p. 104), ao contrário, é entendido aqui como um instrumento que possibilita a interação do usuário/leitor com o conteúdo, pela navegação por nós que ligam as mídias do conteúdo.

O livro eletrônico apresenta o que Santaella (2012) denomina de "topologiai" elástica" - que compreende a malha em que ele está inserido, a tipografia, os recursos visuais, interativos etc. -, característica essa que suporta elementos que conferem e determinam atratividade ao texto digital, o qual deixa de ser estático e passa a ser fluido com o objetivo de demarcar e sistematizar as descobertas e o que se tem pesquisado acerca do tema.

\footnotetext{
* Universidade Federal de Santa Catarina. Imeio: berenice@cce.ufsc.br.

* Universidade Federal de Santa Catarina. Imeio: gabriela.dame@posgrad.ufsc.br.

${ }^{1}$ (to.po.lo.gi.a) sf. 1. Descrição exata e minuciosa de um lugar (TOPOLOGIA, 2012).
}

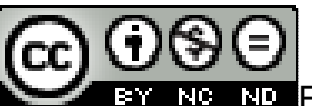

Texto Digital, Florianópolis, v. 9, n. 2, p. 35-51, jul./dez 2013. ANO. ISSNe: 1807-9288 
A problemática que envolve esse tema é a verificação da necessidade do estudo sobre o processo cognitivo envolvido durante a leitura nesse formato, com o objetivo de identificação de parâmetros para que em contextos de projeto possam ser priorizadas a experiência de leitura ativa e as relações entre texto escrito e recursos hipermidiáticos, ${ }^{2}$ linguagem possível nessa formatação. Portanto, para o design de interfaces destinadas à leitura e sobretudo, para a configuração de livros digitais o estudo dos modos de leitura é fundamental.

Para essa abordagem, utilizou-se a metodologia da revisão integrativa, apresentada no tópico do desenvolvimento, a qual é dividida em seções que descrevem suas etapas e a conceituação dos termos pesquisados. Subsequentemente está a seção de discussão que conclui o artigo elaborado, analisando criticamente as informações levantadas como relevantes para continuidade e fundamentação do projeto de pesquisa de dissertação das autoras.

\section{0 livro eletrônico no atual cenário das tecnologias}

No cenário mundial, o impacto das tecnologias nas sociedades e nas suas instituições transforma a relação com o conhecimento. O desenvolvimento de

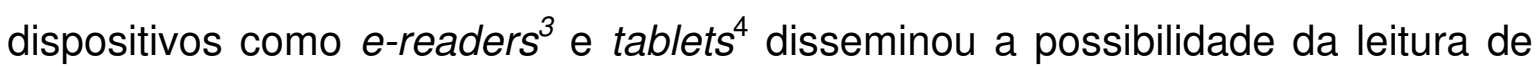
textos digitais. O livro eletrônico, globalmente conhecido como e-book - do acrônimo electronic book, tal como Procópio (2010, p. 26) nos define -, ganha ampla visibilidade nesse processo, pois "permite o acesso instantâneo a milhares de documentos digitais".

\footnotetext{
${ }^{2}$ A hipermídia, linguagem suportada, principalmente, no ciberespaço, é uma combinação de mídias que compõe a narrativa, que se utiliza de hipertexto (texto não linear que interliga blocos de informação verbal) aliado a imagens estáticas ou em movimento e ainda links que relacionam e direcionam o leitor a uma navegação por meio do conteúdo ali proposto (JOHNSON, 2001).

${ }^{3} \mathrm{Um}$ e-reader ou e-book reader é um aplicativo ou dispositivo para leitura de publicações digitais (TECHTERMS.COM, 2012a).

4 Tablets podem ser definidos como computadores portáteis que usam a tela sensível ao toque como dispositivo de input primário. A maioria é bem mais leve e menor que a média dos laptops (TECHTERMS.COM, 2012b).
} 
Segundo Procópio (2008), um texto digital que pode ser dividido em títulos e capítulos pode ser configurado em um livro e sua demanda tem aumentado nos últimos anos, tendo em vista a tendência ecológica e o lançamento de novos dispositivos portáteis de leitura, tais como e-readers, tablets e até mesmo smartphones (PROCÓPIO, 2010). Perante esse cenário, muitos fenômenos temse observado: "Apesar da desaceleração da economia ter afetado o mercado de PCs, os tablets mantiveram o ritmo acelerado de crescimento. É um número recorde impulsionado pela grande quantidade de dispositivos com preços inferiores a R $\$ 1$ mil introduzidos no mercado", afirma Attila Belavary, analista de mercado da IDC Brasil (REVOLUÇÃO EBOOK, 2012a, [s.p.]).

Esses dispositivos facilitam a compra de livros, até por impulso. O cenário torna 0 valor em média $30 \%$ mais barato e possibilita a condensação de bibliotecas inteiras em apenas um dispositivo; essas são só algumas das potencialidades, para ilustrar o advento do formato digital na literatura (PROCÓPIO, 2010).

Recentes números publicados no website Revolução eBook (REVOLUÇÃO EBOOK, 2012b) por Eduardo Melo, em 06 novembro de 2012, mostram que "o número de livros auto-publicados produzidos anualmente nos EUA quase triplicou, crescendo $287 \%$ desde 2006, com 235.625 títulos impressos e lançados em 2011, de acordo com uma nova análise de dados de Bowker. O maior aumento, porém, está sendo percebido nos ebooks" (REVOLUÇÃO EBOOK, 2012b, [s. p.]).

Nesse atual cenário em que o sistema editorial quebra seus fluxos tradicionais e iniciativas de autoria e autopublicação se multiplicam, vive-se um momento de transição e apropriação desses novos formatos, modalidades de interação e leitura.

Em 2011, a produção de ebooks auto-publicados nos EUA foi de 87.201, um aumento de $129 \%$ em relação a 2006 , contra $33 \%$ de crescimento na auto-publicação impressa. Enquanto a auto-publicação é basicamente o autor publicando por conta própria, um punhado de grandes empresas controla este mercado nos EUA. (MELO, 2012, p. 22). 


\subsection{E-book interativo}

No contexto do livro digital, as qualidades interativas são comunicadas a partir da sua interface - elemento que transcende a configuração visual de um sistema, mas que quase sempre se funde a ela na busca por materialidade.

A interface é o espaço de comunicação entre o usuário e o sistema. Para Bonsiepe (1997, p. 10), a interface representa a mediação da interação entre o usuário e o objeto (material ou imaterial) e deve 'conversar' com o usuário, mostrando-lhe como interagir com o objeto.

A ideia básica de interface sugere uma superfície limítrofe entre dois corpos ou espaços. A interface, no entanto, vai além de uma simples separação; indica a possibilidade de adaptação, interconexão, comunicação entre dois ou mais sistemas, equipamentos, unidades etc. que, de alguma forma, apresentem diferenças ou incompatibilidades funcionais (COELHO; FARBIARZ; FARBIARZ, 2008, p. 208).

No livro interativo, o conceito de interface permeia o conteúdo formatado e o aplicativo de leitura, pois é onde ocorre a interação. Vê-se assim que a interface tem a função de construir uma especificidade que facilite a interação ${ }^{5}$ entre usuário e sistema, e não a de representar uma realidade existente.

\subsection{0 livro numa perspectiva conceitual}

O conceito de livro é resultante de um processo "cultural, social e econômico" (FURTADO, 2006, p. 22)

\footnotetext{
5 Padovani e Moura (2008) dizem que interação refere-se ao processo de comunicação estabelecido entre o usuário e o sistema durante a realização de tarefas, enquanto interatividade consiste em uma característica variável que se refere o quão proativo a configuração do sistema permite que o usuário seja durante a interação, podendo ser medida em níveis.
} 
O livro seria assim como que o sintoma das circunstâncias da nossa cultura num período de rápida transformação, mobilizando relações complexas entre processos de desenvolvimento tecnológico, práticas e instituições sociais e culturais, e a instauração de hierarquias e formas de dominação material e simbólica.

Kant distingue fundamentalmente o livro como objeto material, que pertence ao comprador, e o livro como discurso dirigido ao público, fazendo parte da propriedade de seu autor e só podendo ser posto em circulação por aqueles que são seus "mandatários" (KANT, 1796 apud CHARTIER, 2011b, p. 262).

Assim, o livro é um objeto (material) que está inserido em uma dinâmica comercial e industrial que "mantém, ainda assim, características imateriais vinculadas ao conhecimento e ao saber disponibilizado pelo autor", como nos afirma Oliveira (2012, [s.p.]), quando, em seu artigo premiado pela Câmara Brasileira do Livro, ilustra que Chartier (2009 apud OLIVEIRA, 2012, [s.p.]):

constrói sua visão sobre o livro por meio de autores como Kant, [...] quando esse diferenciava o livro em duas naturezas crendo ser "[...] ao mesmo tempo, um bem material do qual o comprador torna-se o legítimo proprietário, e um discurso do qual o autor conserva a propriedade 'não obstante a reprodução' [...]".

Nesse sentido, damos continuidade à configuração e ao enquadramento do livro, mesmo em formato eletrônico, como "objeto do saber", uma das figuras de aprendizagem que Charlot (2000, p. 66) propõe: "o livro é um objeto do saber, objeto onde o saber está incorporado", tal quais outros objetos, como os monumentos, as obras de arte, os programas de televisão etc.

Charlot entende que, diante desses objetos do saber, o indivíduo que aprende estabelece diferentes relações, o que indica diferentes processos de aprendizagem e apropriação. Trata-se assim de uma relação epistêmica em que o aprender configura-se numa atividade em situação. 
A relação com o livro se dá em um momento da sua história pessoal e da história da humanidade, em condições socioculturais diversas, sob diferentes mediações de outras pessoas. A relação com o saber-livro é, portanto, uma relação com o mundo, em um sentido geral, com os mundos particulares nos quais o leitor vive e aprende. Do ponto de vista epistêmico, a aprendizagem pode ocorrer quando da apropriação de um objeto virtual (o saber), encarnado em objetos empíricos (livro impresso, livro eletrônico etc.), abrigado em locais (bibliotecas, escolas) e possuído por pessoas que já percorreram um caminho (professores, pais etc.). Aprender é, então, tomar posse desses saberes-objetos, dos conteúdos intelectuais que podem ser designados de maneira precisa ou imprecisa. O aprender passa por essa apropriação de algo que não se possui e que está inscrito em objetos, pessoas, locais... A mediação é tudo aquilo ou aqueles que indicam o caminho a ser percorrido, por meio do simples servir de modelo ou até dos ensinamentos, ação deliberada de ensinar ou transmitir ao outro aquilo que se sabe. Nesse caso, passa-se da não posse à posse, da identificação de um saber virtual à sua apropriação. O livro torna-se saber, pois é expressão materializada pela escrita e fica à disposição independentemente de um sujeito (CHARLOT, 2000, p. 68).

Conhecimento, conforme uma das definições do dicionário Houaiss, "é ato ou efeito de apreender intelectualmente, de perceber um fato ou uma verdade; cognição, percepção" (CONHECIMENTO, 2013, [s.p.]). Segundo Fialho (2001, p. 109), corresponde a uma codificação de informações em linguagem natural, "capazes de transformar lembranças puras em lembranças imagens". Pode ser sobre objetos (organizados em ordem semântica), situações (expressas por esquemas) e ações (os procedimentos). Este último pode ser configurado em uma estrutura que se assemelha a um mapeamento real, mas se descreve no mapa cognitivo. 


\subsection{Pressupostos da pesquisa em leitura interativa em meio eletrônico}

Que processos estão envolvidos na leitura? Segundo Rosa Bizarro (2000, p. 466467), "a leitura pressupõe o processamento da informação de uma classe de símbolos que constituem expressões no intercâmbio comunicativo que tem lugar através da linguagem".

De acordo com Preece et al. (2005), os processos cognitivos acontecem na mente humana durante a realização de atividades diárias, envolvendo atenção, percepção, memória (de curto e longo prazo), aprendizado, leitura, fala, audição e resolução de problemas.

As autoras complementam que a "linguagem escrita é permanente, e a falada, transitória”, considerando que é possível ler a informação em um outro momento se ela não for entendida da primeira vez, o que não ocorre com a informação falada (pode ser possível se o sistema disponibilizar um dispositivo para a repetição da informação sonora) (PREECE et al., 2005, p. 107-108). Também argumentam que o texto falado segue o tempo do narrador, enquanto o escrito pode ser lido dinamicamente; ouvir exige menos carga cognitiva do que ler ou falar.

Em estudo anterior, Damé e Gonçalves (2012, p. 422) afirmaram que "a criação de novos espaços, possíveis para a leitura, foi possível porque houve modificação e desenvolvimento dos suportes". Assim, tanto os textos como a aparência do livro sofreram modificação, ganhando novos formatos potencializados pelo "lançamento de diversos dispositivos tecnológicos que servem como suporte móvel para os títulos digitais".

\section{Procedimentos metodológicos}

Tendo em vista a temática proposta, efetuou-se um estudo exploratório e descritivo de abordagem qualitativa, fundamentado por meio da revisão integrativa, a qual pode ser definida como 
um método de pesquisa que permite a busca, a avaliação crítica e a síntese das evidências disponíveis do tema investigado, sendo o seu produto final o estado atual do conhecimento do tema investigado e a identificação de lacunas que direcionam para o desenvolvimento de futuras pesquisas. (MENDES; SILVEIRA; GALVÃO, 2008, p. 759)

A revisão integrativa se constitui das etapas apresentadas nas subseções a seguir e são baseadas na proposta de Botelho, Cunha e Macedo (2011).

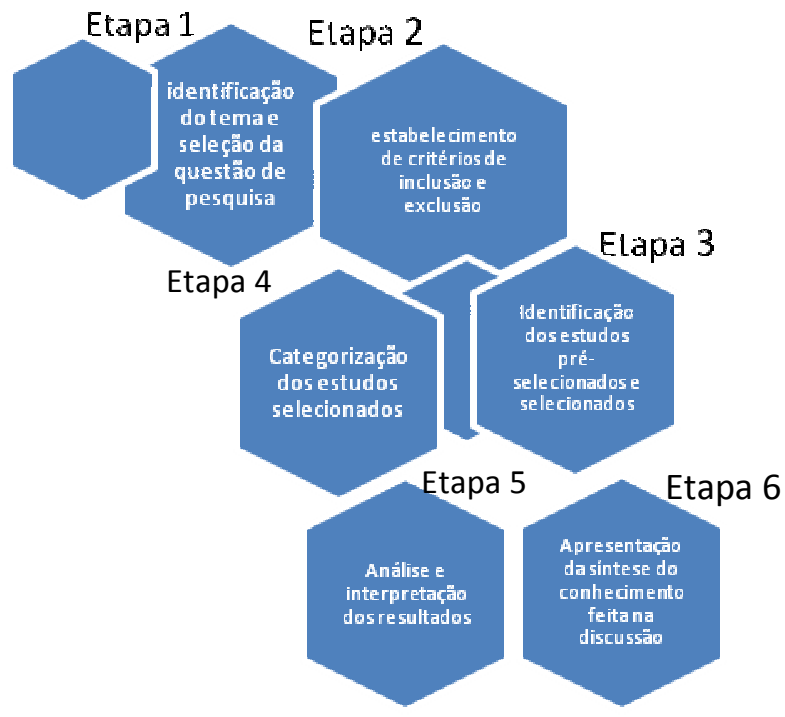

Figura 1: Esquema das etapas da revisão integrativa Fonte: Adaptado de: Botelho, Cunha e Macedo (2011).

Etapa 1: o tema escolhido foi a leitura em livro eletrônico, apresentado na introdução e na contextualização deste artigo, juntamente com a questão da pesquisa, que pretende identificar quais as características da leitura em livro eletrônico.

Etapa 2: planejamento e coleta de publicações que consideram os critérios de inclusão definidos para a seleção dos artigos, a saber: artigos publicados em inglês, na íntegra, que incluíssem no tópico reading as palavras-chave "e-book + interact*". Esses artigos foram identificados por terem sido publicados nos últimos cinco anos (2008-2013), disponibilizados nos bancos de dados indexados no 
Portal Capes, cujas áreas de conhecimento são Ciências Sociais Aplicadas, Letras e Artes.

Segue o número de artigos resultantes desta pesquisa, de acordo com as bases de dados:

a) OneFile (GALE) (10); b) ERIC (U.S. Dept. of Education) (4); c) Science Citation Index Expanded (Web of Science) (2); d) SpringerLink (2); e) SAGE Journals (1); f) Arts \& Sciences (JSTOR) (1); g) SciVerse ScienceDirect (Elsevier) (1); e h) Social Sciences Citation Index (Web of Science) (1).

Etapa 3: identificação dos estudos pré-selecionados e selecionados. Os artigos localizados foram categorizados no software EndNote X6 para melhor identificação de conteúdo e referências.

Etapa 4: categorização dos estudos selecionados. A seleção dos estudos deu-se pela identificação nos resumos (abstracts) de que a metodologia do estudo envolvia o público adulto como público leitor.

Etapa 5: análise e interpretação dos resultados. Foi feita uma análise crítica das informações contidas nos artigos selecionados pela sua metodologia $e$ conceituações.

Etapa 6: apresentação da revisão/síntese do conhecimento feita na discussão que compõe a próxima seção.

Os aspectos levantados na pesquisa de revisão integrativa são apresentados a seguir, na quarta seção deste artigo, através de uma análise crítica dos pontos convergentes no cruzamento das informações dos estudos.

\section{Classificação e discussão dos principais conceitos}


Entre os artigos selecionados, destacaram-se os estudos de Siegenthaler et al. (2011), que propõem a comparação da leitura num espectro ergonômico de seu desempenho, com análise de tempo de leitura, movimento de olhos, iluminação e contraste, fixação etc., em cinco dispositivos eletrônicos de leitura e em papel impresso. Foram gravados 10 participantes com média de idade de 42 anos, nivelados por experiência com mídia (nenhuma anterior). Esse experimento constava de três partes: teste de legibilidade com eye-tracking antes e depois; questionários; execução de tarefas e descanso de 15 minutos.

Os resultados mostram que o comportamento de leitura, quando feita em um ereader de tela e-ink, ${ }^{6}$ é muito semelhante ao comportamento de leitura em papel impresso, em contraste com LCD-displays, que têm sido associados com deficiência de desempenho de leitura. Os pesquisadores concluíram que telas eink são um marco importante no campo da leitura.

Liesaputra e Witten (2012) apresentam o desenvolvimento dos suportes para leitura através dos séculos até os documentos digitais. Abordam a personalização do texto digital, aspectos de compreensão, navegação e localização, e identificam que o maior problema encontrado em textos digitais é a homogeneidade, já que eles tendem a se parecer muito e dificulta ao usuário leitor a localização. Nesse estudo é proposto um aplicativo de leitura chamado Realistic Book, desenvolvido em flash para a verificação se a emulação do livro impresso auxilia na leitura do livro eletrônico.

Os mapas cognitivos, norteadores do estudo de Li, Chen e Yang (2013), representam 0 arranjo espacial entre os objetos em um ambiente que, presumidamente, é similar a um mapa real (SPENCE, 1999 apud LI; CHEN; YANG, 2013). Eles são construídos, a princípio, para uma atividade de

\footnotetext{
${ }^{6}$ E-ink: "O papel eletrônico, tinta eletrônica ou tinta eletroforética é o termo que designa tecnologias que procuram imitar o papel convencional com uma impressão eletrônica de textos e imagens e que podem ser facilmente editadas" (E-INK, 2013, [s.p.]).
} 
navegação, no modelo "Ponto de referência, Rota, Inspeção" (LRS - Landmark, Route, Survey). O mapa cognitivo é construído através de três passos:

\begin{abstract}
(a) identificação de pontos de referência - objetos ou lugares - que servem de referência durante a navegação, esses pontos de referência como (b) rotas de conhecimento para descrever temporariamente sequências de navegação de um ponto de referência a outro e finalmente as pessoas organizam o todo numa representação geral que gera um (c) mapa de conhecimento do ambiente. (FOO et al., 2005 apud LI; CHEN; YANG, 2013, [s.p.]; VOROS; ROUET; PLEH, 2011 apud LI; CHEN; YANG, 2013, [s.p.])
\end{abstract}

Segundo Liesaputra e Witten (2012), a opinião sobre a emulação da aparência de livros impressos em meio eletrônico é dividida: alguns pesquisadores argumentam que é desnecessário paginar documentos ou manter o leiaute da página impressa (ROWLAND et al., 1995 apud LIESAPUTRA; WITTEN, 2012; NIELSEN, 1998; KOL AND SCHCOLNIK, 2000; SHNEIDERMAN, 1998; McKNIGHT et al., 1991 apud LIESAPUTRA; WITTEN, 2012), enquanto outros acreditam que, com treino e prática, usuários não ficarão mais contando com o tradicional modelo de livro para localizar a informação (LIESAPUTRA; WITTEN, 2012).

De toda forma, em seu estudo, concluem que pessoas raramente leem de maneira linear e buscam por informações do que estão lendo na interface do documento - seja no impresso, seja no digital - para saber sobre a sua posição atual, seu volume (extensão de leitura), qual o próximo passo e como ir a partes que não estão sendo visualizadas.

No estudo desenvolvido por Siegenthaler et al. (2011), há a tentativa de comparar os modos de leitura em diferentes dispositivos e ainda no livro impresso.

Estudos sobre mapas cognitivos em e-books são raros, nesse artigo de Li, Chen e Yang (2013) percebe-se que o desenvolvimento de aplicativos que possibilitem essa estruturação/mapeamento cognitivo contribui positivamente para a leitura ativa. Com sistema de pré-leitura e leitura que informam se o leitor já leu aquele conteúdo anteriormente (isso baseado nas informações da base de dados do 
aplicativo), o aplicativo já transfere o leitor ao modo de visualização que the permite saber quantas páginas estão disponíveis naquele capítulo, se possui ilustrações etc.

A pesquisa apresentada no artigo de Moyer (2011), feita com estudantes universitárias, concluiu que, pelos critérios de engajamento e motivação (GUTHRIE et al., 1996 apud MOYER, 2011), não houve diferença na leitura das três modalidades de textos (audiobook, e-books e livros impressos) e esses fatores afetam diretamente a leitura de lazer (MOYER, 2011, p. 254).

Embora as tecnologias estejam sendo desenvolvidas para aprimorar a leitura em tela, estudos recentes têm mostrado que o suporte à leitura, para uma leitura ativa, se mantém impróprio ou insuficiente (LI; CHEN; YANG, 2013, p. 32).

Alguns estudos têm examinado como as pessoas constroem e usam mapas cognitivos na leitura de hipertexto. Por exemplo, Payne e Reader (2006 apud LI; CHEN; YANG, 2013, p. 33) observaram que os leitores constroem uma representação mental do mapeamento entre o conteúdo do documento e sua estrutura durante os processos de leitura e consultam a representação de muitos aspectos do uso de texto, como releitura e atualização de conhecimentos.
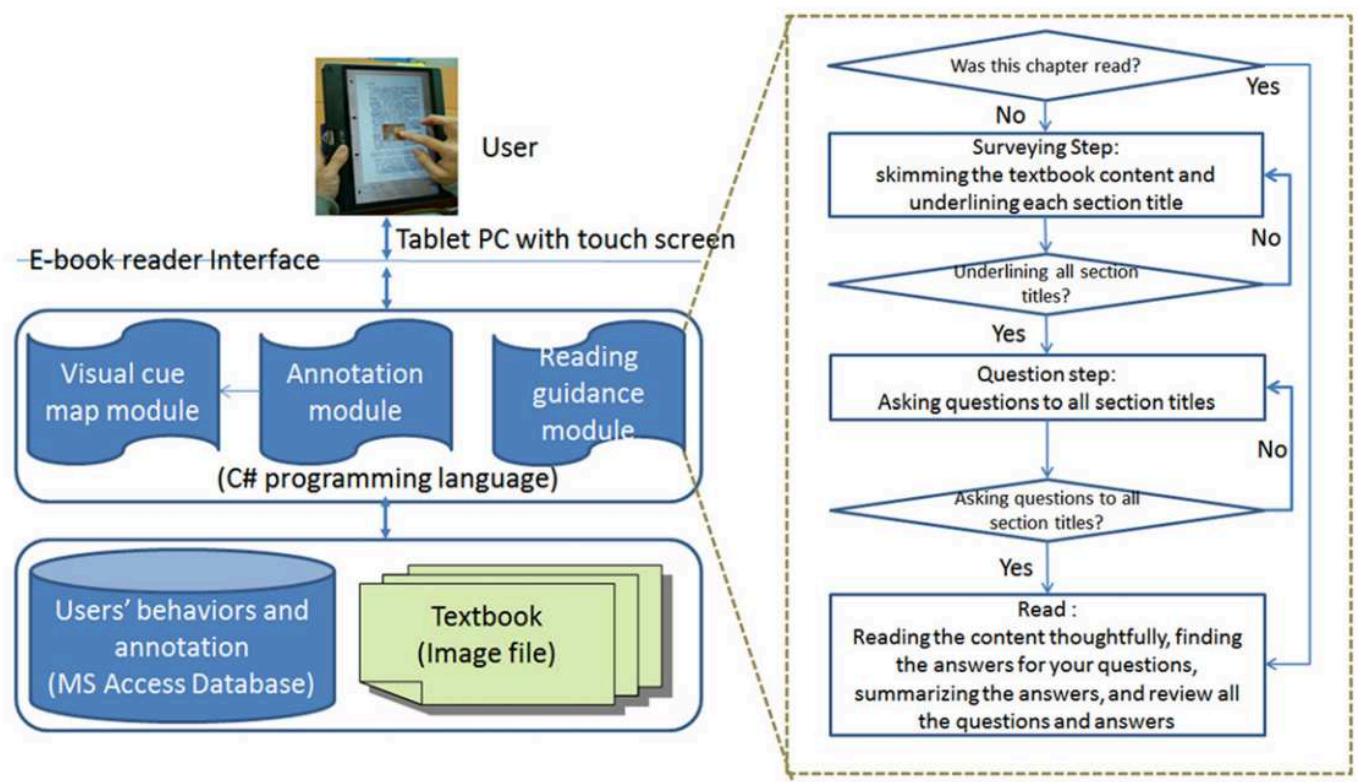
Figura 2: Arquitetura do sistema do aplicativo leitor proposto, baseado nos mapas cognitivos interpretados.

Fonte: Li, Chen e Yang (2013, p. 34).

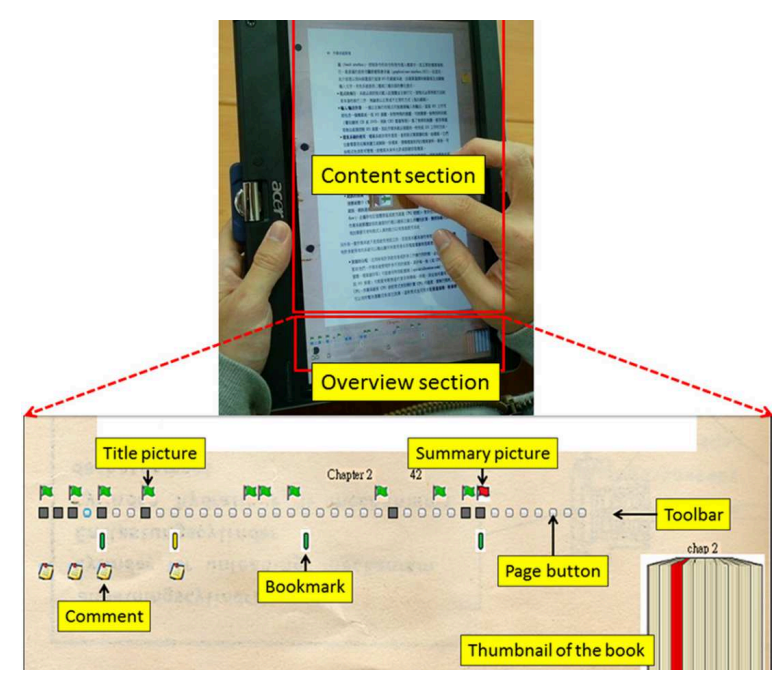

Figura 3: Interface do aplicativo leitor proposto, baseado nos mapas cognitivos gerados Fonte: Li, Chen e Yang (2013, p. 35).

Certa leitura e facilidades de navegação, como visão geral da estrutura e previsões de link, têm sido comprovadamente ferramentas para melhorar a leitura e o desempenho de navegação em sistemas de hipertexto, aparentemente porque essas promovem a construção de mapas cognitivos (LI; CHEN; YANG, 2013, p. 34).

\section{Conclusão}

A revisão integrativa sistematizou informações a respeito de como se tem pesquisado sobre a leitura em meio eletrônico, essa, ainda linear ou comparativa, contribuindo para o conhecimento de técnicas, metodologias, instrumentos e procedimentos que direcionam essas pesquisas.

$\mathrm{Na}$ maior parte dos casos, com a popularização dos livros eletrônicos, os softwares de leitura proporcionam ferramentas que possibilitam anotação, pesquisa, navegação, representação dinâmica de conteúdos e administração de e-books. Pesquisas também têm desenvolvido alguns sistemas de e-books para dar suporte ao compartilhamento de anotações e marcações, como o leitor do 
Kobo, que dá também suporte à colaboração por meio de redes sociais em que o conteúdo pode ser visualizado.

Assim, indica-se como lacuna identificada a leitura em livro interativo especificamente, em linguagem hipermidiática, e não em hipertextos de forma geral. Essa pode ser preenchida com a proposta de pesquisa a ser desenvolvida na dissertação desenvolvida pelas autoras no mestrado em Design e Expressão Gráfica, que buscará responder quais são as especificidades da leitura em e-book interativo no contexto da hipermídia.

\section{FEATURES OF TEXT READING IN ELECTRONIC BOOK: AN INTEGRATIVE REVIEW}

ABSTRACT: This study aimed to develop a critical analysis of the information collected from an integrative review of the key terms related to reading and text in interactive electronic books. From those words, in articles of databases identified from Portal Capes Periodicals aimed to demarcate and systematize the discoveries and research over the last five years. Thus, the research was conducted using the following question: which are the features of the text and, therefore, of the reading in electronic books, from the year 2008, the three most relevant databases found in the search of the keywords defined and revised throughout the process. From the results it was possible to obtain an overview of the theme enunciated and identify gaps for future research. Are still rare studies on the reading experience in interactive electronic book. The studies found differ as to the language of the interface, because reading depends on the configuration of an individual and subjective cognitive map.

KEYWORDS: Electronic book, Hypermedia, Reading, Text.

\section{REFERÊNCIAS}

BEHRENS, L.; ROSEN, L. J. Analysis. In: writing. 4. ed. Harlow: Longman, 2010. p. 188-222.

A sequence for academic

BEYEA, S. Writing an integrative review. AORN Journal, 19 out. 2010. Disponível em: $\quad<$ http://findarticles.com/p/articles/mi_m0FSL/is_n4_v67/ai_20972821/>. Acesso em: 8 dez. 2012.

BIANCAROSA, G.; GRIFFITHS, G. G. Technology tools to support reading in the digital age. The Future of Children Fall 2012: p. 139+. Academic OneFile. Disponível em: <http://go.galegroup.com.ez46. periodicos.capes.gov.br/ps/i.do?id=GALE\%7CA30 $6859396 \& v=2.1 \& u=$ capes58\&it=r\&p=AONE\&sw=w>. Acesso em 31 jan. 2013.

BONSIEPE, G. Design do material ao digital. Florianópolis: FIESC/IEL, 1997. 
BOTELHO, L, L. R.; CUNHA, C. C. de A.; MACEDO, M. O método da revisão integrativa nos estudos organizacionais. Gestão e Sociedade, Belo Horizonte, v. 5, n. 11, p. 121-136, maio/ago. 2011.

CHARLOT, B. Da relação com o saber: elementos para uma teoria. Porto Alegre: Artmed, 2000.

CHARTIER, R. O livro e seus poderes (séculos XV a XVIII). In: COUTINHO, E. G.; GONÇALVES, M. S. (Orgs.). Letra impressa: comunicação, cultura e sociedade. Porto Alegre: Sulina, 2009.

CHARTIER, R. Aula inaugural no Collège de France. In: ROCHA, J. C. C. de (Org.). Roger Chartier a força das representações: história e ficção. Chapecó: Argos, 2011a. p. 249-285.

. Uma trajetória intelectual: livros, leituras, literaturas. In: ROCHA, J. C. C. de (Org.). Roger Chartier a força das representações: história e ficção. Chapecó: Argos, 2011b. p. 21-53.

COELHO, L. A.; FARBIARZ, J. L.; FARBIARZ, A. (Orgs.). Os lugares do Design na leitura. Teresópolis: Novas Idéias/FAPERJ, 2008.

CONHECIMENTO. In: Grande dicionário Houaiss da língua portuguesa. Disponível em: <http://houaiss.uol.com.br/busca?palavra=conhecimento>. Acesso em: 10 fev. 2013.

DAMÉ; G.; GONÇALVES, B. Livro eletrônico: a construção do saber interativo. In: 4 CONGRESSO SUL-AMERICANO DE DESIGN DE INTERAÇÃO, São Paulo, 2012. Anais... São Paulo: Bloucher, 2012. p. 418-427.

E-INK. In: ENCICLOPÉDIA colaborativa. Disponível em: <http://www.ebookpedia.com.br/wiki/E-ink>. Acesso em: 24 fev. 2013.

FARBIARZ, A. Entre o linear e o não linear do texto impresso ao eletrônico. In: FARBIARZ, J. L.; FARBIARZ, A.; COELHO, L. A. (Orgs.). Os lugares do Design na leitura. Teresópolis: Novas Idéias/FAPERJ, 2008. p. 103-110.

FIALHO, F. Ciências da cognição. Florianópolis: Insular, 2001.

FURTADO, J. A. O papel e o pixel. Do impresso ao digital: continuidades e transformações. Florianópolis: Escritório do Livro, 2006.

GOLFETTO, I. F.; GONÇALVES, B. S. Processo de leitura em edições digitais de revistas. In: 6 CONGRESSO INTERNACIONAL DE PESQUISA EM DESIGN. Anais... Lisboa, 10-12 out. 2011. Disponível em: <http://www.ciped6.fa.utl.pt/>. Acesso em: 10 fev. 2013. 
GUTHRIE, J. T. et al. Growth of literacy engagement: changes in motivations and strategies during concept oriented reading instruction. Reading Research Quarterly, v. 3, n. 31, p. 306-332, 1996.

HASLAM, A. O livro e o designer II: como criar e produzir livros. Tradução de Juliana Saad e Sérgio Rossi Filho. São Paulo: Edições Rosari, 2007.

JOHNSON, S. A cultura da interface. Rio de Janeiro: Jorge Zahar, 2001.

LI, L.-Y.; CHEN, G.-D.; YANG, S.-J. Construction of cognitive maps to improve ebook reading and navigation. Computers \& Education, n. 60, p. 32-39, 2013.

LIESAPUTRA, V.; WITTEN, I. H. Realistic electronic books. Int. J. HumanComputer Studies, n. 70, p. 588-610, 2012.

MELO, E. Auto-publicação ganha força com ebooks. In: SIMPLÍSSIMO LIVROS. O mercado de e-books no Brasil. Porto Alegre: Simplíssimo Livros, 2012. p. 22.

MENDES, K. D. S.; SILVEIRA, R. C. de C. P.; GALVÃO, C. M. Revisão integrativa: método de pesquisa para a incorporação de evidências na saúde e na enfermagem. Texto Contexto Enferm, Florianópolis, v. 4, n. 17, p. 758-764, out./dez. 2008.

MOYER, J. E. What does it really mean to "read" a text? Digital Literacies Journal of Adolescent \& Adult Literacy, v. 5, n. 3, p. 253-256, Nov. 2011.

OLIVEIRA, D. A. de. O papel do editor gaúcho frente à produção e comercialização dos livros digitais. In: III CONGRESSO INTERNACIONAL CBL DO LIVRO DIGITAL, maio 2012, São Paulo. Anais... São Paulo, 2012.

PADOVANI, S. Usabilidade de sistemas de navegação em hipermídia. In: III

CONAHPA, 2008, São Paulo. Anais... São Paulo, 2008.

PADOVANI, S.; MOURA, D. Navegação em hipermídia: uma abordagem centrada no usuário. São Paulo: Ciência Moderna, 2008.

PORTAL CAPES DE PERIÓDICOS. Disponível em: <http://www.periodicos.capes.gov.br>. Acesso em: 10 fev. 2013.

PIRES, J. A. Leitura e virtualidade: tecendo entre as linhas da narrativa. In: COELHO, L. A. L.; FARBIARZ, A. (Orgs.). Design: olhares sobre o livro. Teresópolis: Novas Idéias, 2010.

PREECE, J. et al. Design de interação: além da interação homem-computador. Porto Alegre: Bookman, 2005. 
PROCÓPIO, E. Os diversos formatos dos arquivos de livros eletrônicos. 2006. Disponível em: <http://ebookpress.wordpress.com/2008/03/01/formatos/>. Acesso: 20 nov. 2012.

. O livro na era digital. São Paulo: Giz Editorial, 2010.

QUEVEDO, S.; ULBRICHT, V. Narrativa versus hipermídia: contribuições a um novo saber. In: VANZIN, T.; DANDOLINI, G. Mídias do conhecimento. Florianópolis: Pandion, 2011. p. 195-219.

REVOLUÇÃO EBOOK. E dê-lhe tablets pra galera. Disponível em: <http://revolucaoebook.com.br/lhe-tablets-pra-galera/>. Acesso em: 2 nov. 2012a.

REVOLUÇÃO EBOOK. Mercado mundial de ebooks. Disponível em: $<$ http://revolucaoebook.com.br/segundo-bowker-brasil-terceiro-maior-mercadoebooks/>. Acesso em: 2 nov. 2012b.

ROSA BIZARRO, O. F. A leitura como um processo cognitivo. 2000. Disponível em: <http://ler.letras.up.pt/uploads/ficheiros/8471.pdf>. Acesso em: 12 jul. 2012.

SANTAELLA, L. Navegar no ciberespaço. São Paulo: Paulus, 2009.

. Condições da ciberliteratura. In: I SIMPÓSIO INTERNACIONAL E V SIMPÓSIO NACIONAL DE LITERATURA E INFORMÁTICA, Florianópolis, 20-22 nov. 2012. Disponível em: <http://simposioliteraturainformatica.ufsc.br/>. Acesso em: 10 dez. 2012.

SIEGENTHALER, E. et al. Comparing reading processes on e-ink displays and print. Displays, n. 32, p. 268-273, 2011.

TECHTERMS.COM. E-reader. Disponível em: <http://www.techterms.com/definition/ereader>. Acesso em: 20 out. 2012a.

- Tablet. Disponível em: <http://www.techterms.com/definition/tablet>. Acesso em: 20 out. $2012 b$.

TOPOLOGIA. In: DICIONÁRIO Aulete. Disponível em: <http://aulete.uol.com.br/topografia\#ixzz2BIPLMgNf>. Acesso em: 9 nov. 2012.

Texto recebido em 28/10/2013.

Texto aprovado em 29/11/2013. 